\title{
Electrophysiological findings in frequency-dependent left bundle-branch block
}

\author{
H. Neuss, J. Thormann, and M. Schlepper \\ From the Kerckhoff-Klinik, Bad Nauheim, W. Germany
}

Seven patients with frequency-dependent left bundle-branch block were studied with programmed atrial stimulation. Cardiac conduction was analysed by His bundle recordings. Atrial driving rate was gradually increased by shortening the driving cycle length by steps of 10 msec from sinus rhythm up to a cycle length at which left bundle-branch block appeared. Decreasing heart rate, left bundle-branch persisted up to a cycle length which was always 80 to 170 msec longer than that found when heart rate was increased ('zone of linking'). In all patients a depression of conductivity ('postdrive depression') after a driving period of 2 minutes (ventricular rate: 100 to $170 /$ min) was found.

Full recovery time of the left bundle-branch did not shorten in 6 patients when heart rate was accelerated. In 4 patients even an increase of full recovery time was found if basic heart rate was within the zone of linking. In 3 patients gap III phenomena were observed and in 2 patients a paradoxical improvement of conduction in the left bundle-branch appeared at higher rates.

The underlying mechanism of the observed phenomena might be a frequency-dependent reduction of the upstroke velocity of action potentials. Alternative mechanisms are discussed.

In I913 Lewis gave an account of a 31-year-old patient with a transient left bundle-branch block. Since then this condition has been dealt with in numerous clinical reports (Comeau, Hamilton, and White, 1938; Vesell, 194I; Bauer, 1964) and more recent attention was drawn to the phenomenon by Rosenbaum et al. (1973). It was common to explain the inconsistency of left bundle-branch patterns by morphological and functional alterations, and changes in heart rate were considered a most important factor in the appearance and disappearance of blockade. Alterations in heart rate had previously been induced by indirect measures only (carotid sinus pressure, Valsalva manoeuvre, amyl nitrite inhaltion, atropine medication, etc.). Using these techniques it was impossible, however, to separate the effects of alterations in heart rate from those concomitantly induced by the autonomic nervous system. It is surprising that the frequency dependence of the phenomena has not been systematically investigated by electrical stimulation. Using this method, associated with intracardiac electrography, one can arrive at a more objective evaluation regarding the frequency dependence of bundlebranch block. For example, specifically premature atrial depolarizations can be used to determine the refractory periods of the involved branch at different heart rates.

\section{Subjects and methods}

Seven patients with intermittent left bundle-branch block were admitted to the study. All patients had undisturbed intraventricular conduction at sinus rhythm at the beginning of the investigation. The patients consented to the electrophysiological studies and were in a non-sedated state and without antiarrhythmic medication at the time of examination. A 5-polar-catheter was placed via the right femoral vein at the right side of the ventricular septum adjacent to the bundle of His according to Scherlag et al. (1969). Two favourable electrodes were selected to record filtered (40 to $200 \mathrm{~Hz}$ ) caudal atrial and His bundle depolarizations. A second catheter with four electrodes (4 F) was positioned via the same femoral vein in the proximity of the sinus node. Two electrodes were used to record the cranial atrial electrogram, while the remaining two electrodes served in atrial stimulation. Simultaneously, several leads of surface electrocardiogram were registered. Surface electrocardiograms and intracardiac electrograms were recorded on magnetic tape and displayed with a paper speed of $100 \mathrm{~mm} / \mathrm{sec}$ using an ink writing system. The atrial stimuli consisted of rectangular impulses of $2.0 \mathrm{msec}$ duration and twice diastolic threshold. Cycle length of 
atrial driving was gradually shortened by steps of Io msec from sinus rhythm up to a frequency at which left bundle-branch block appeared. Similarly, cycle length was increased until left bundle-branch block disappeared. The alterations in heart rate were generally achieved by decreasing or increasing the SS interval (cycle length of driving stimuli) by $100 \mathrm{msec}$ within $30 \mathrm{sec}$. Conductivity of the left bundle-branch was studied in the immediate postdrive period, i.e. right after rapid atrial stimulation was abruptly terminated. The heart rate chosen was well above the critical frequency at which left bundle-branch block appeared. In addition, refractory periods of the atrioventricular conduction system were determined using premature atrial stimuli (Wit et al., I970). Functional refractory period of the atrioventricular node $\left(\right.$ FRP $\left._{\text {AvN }}\right)$ was defined as the shortest possible interval between two His bundle depolarizations $\left(\mathrm{H}_{1} \mathrm{H}_{2}\right)$ produced by premature atrial depolarizations at a specific heart rate. Effective refractory period of the atrioventricular node $\left(\mathrm{ERP}_{\mathrm{AvN}}\right)$ was given by the longest coupling interval for premature atrial deporalizations $\left(A_{1} A_{2}\right)$ which were blocked above the bundle of His. Full recovery time of the left bundle-branch $\left(\mathrm{FRT}_{\mathrm{LBB}}\right)$ was defined by the longest $\mathrm{H}_{1} \mathrm{H}_{2}$ interval with which left bundle-branch block occurs.

\section{Results}

The results of the study are demonstrated by selected examples.

\section{I) Critical frequency range}

a) 'Linking' In Case 6, augmentation of heart rate by shortening of the SS intervals in steps of
Io msec leads to the occurrence of left bundlebranch block at a critical SS interval of $620 \mathrm{msec}$ as demonstrated in Fig. I. Left bundle-branch block, however, persists up to a cycle length of $740 \mathrm{msec}$ when heart rate is gradually decreased in a similar manner. This means, that by accelerating the heart rate, the critical SS interval at which left bundle-branch block appears is shorter than that at which conduction is returned to normal when heart rate is decelerated. In this critical range between the cycle lengths of 740 and $620 \mathrm{msec}$ (heart rate: 82 to $97 / \mathrm{min}$ ), left bundle-branch block as well as undisturbed conduction is observed. This phenomenon was called 'linking' (Rosenbaum et al., 1973).

b) In 2 patients it was apparent that the occurrence of left bundle-branch block, in addition to a critical frequency, also depended on how fast this rate was reached. In Case I heart rate was gradually increased. Starting at a cycle length of $600 \mathrm{msec}(100 / \mathrm{min})$, the critical SS interval of $480 \mathrm{msec}$ was reached after $38 \mathrm{sec}$. Under these conditions left bundle-branch block appeared after the first SS interval of $480 \mathrm{msec}$. When an equal shortening of cycle length was achieved within $8 \mathrm{sec}$, however, left bundle-branch block occurred after 2I SS intervals of $480 \mathrm{msec}$.

c) By increasing heart rate the critical cycle length at which left bundle-branch block appears was $550 \mathrm{msec}$ in Case 2, while it disappears at 710 msec. If, starting at a cycle length of $500 \mathrm{msec}$,
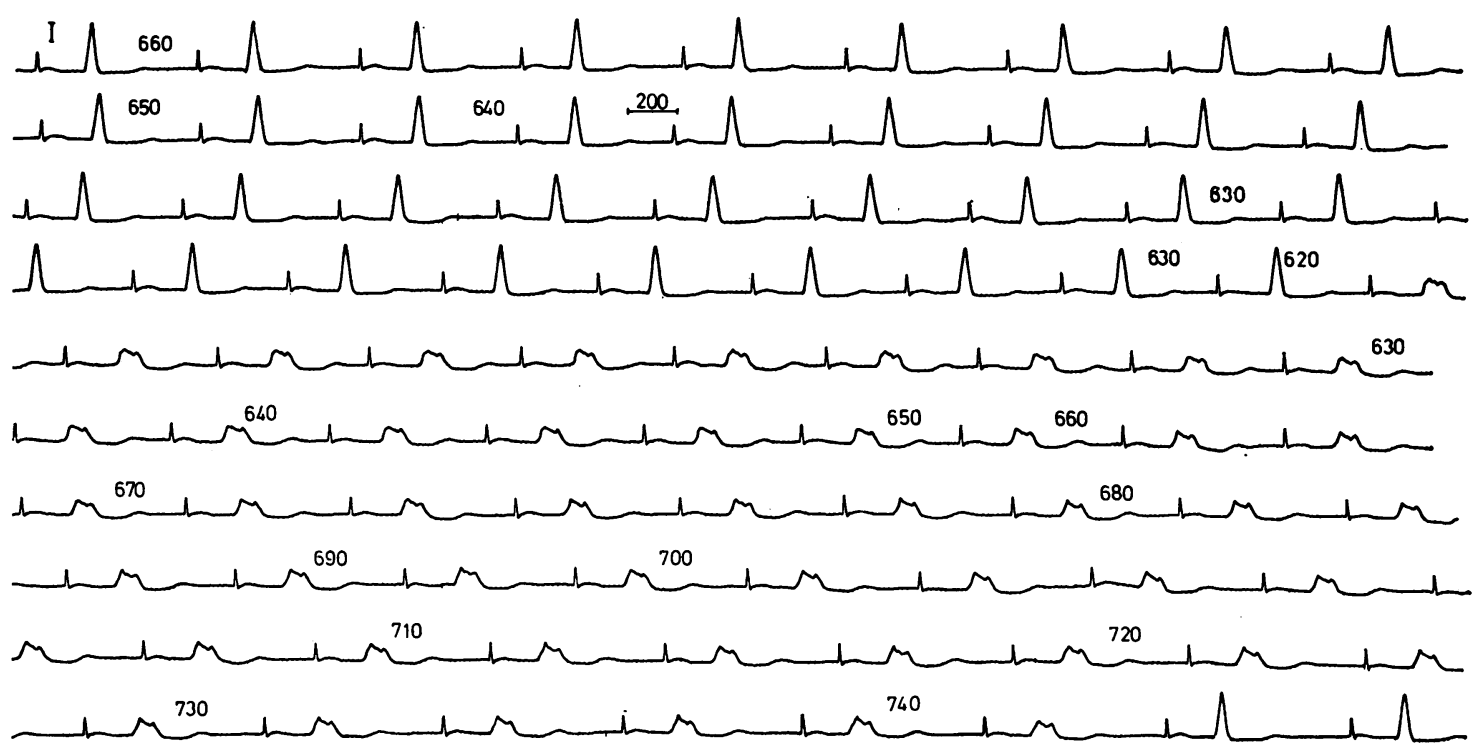

FIG. I Electrocardiogram (I) continuous recording (Case 6). Driving cycle length in msec. 


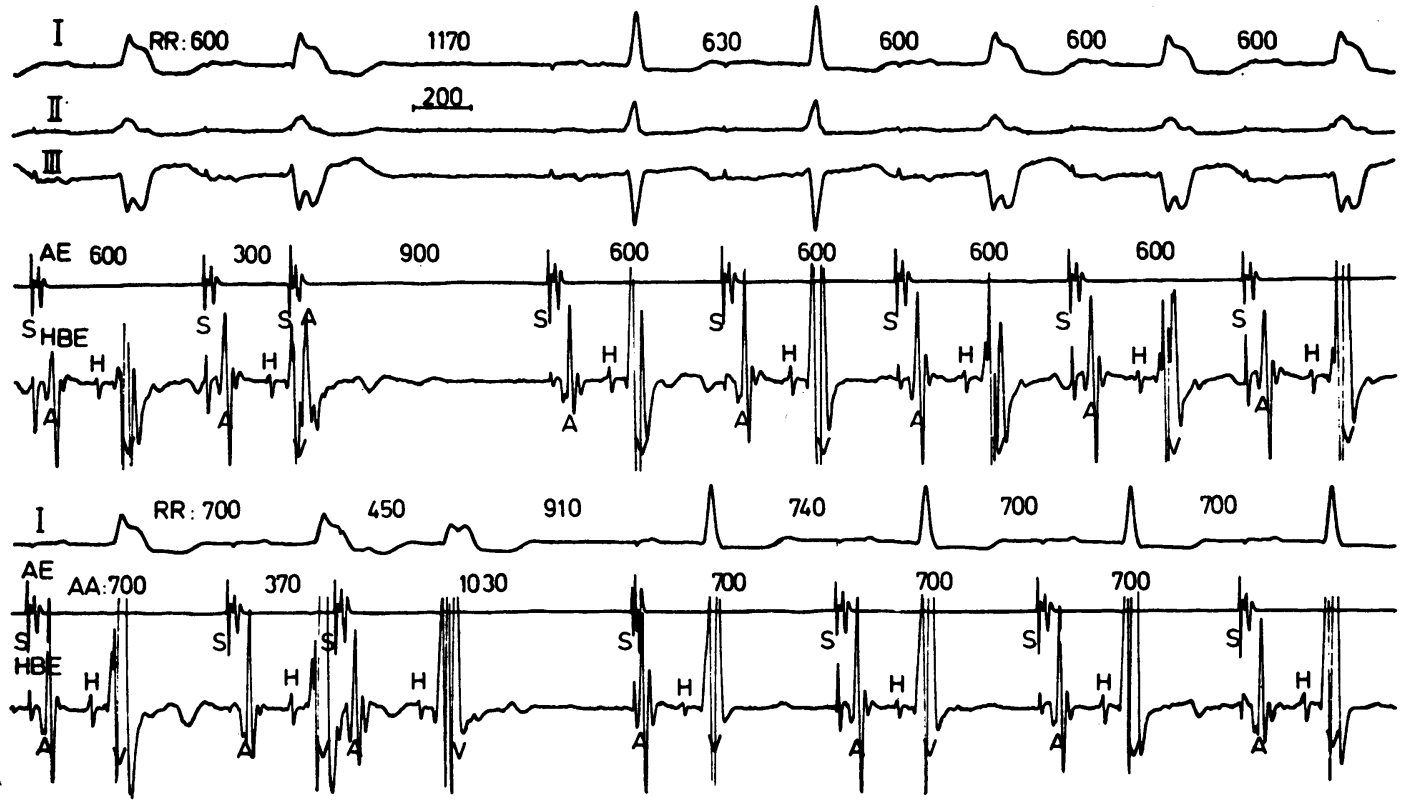

FIG. 2 Electrocardiogram (I, II, III), atrial electrogram $(A E)$, and His bundle electrogram (HBE) from Case 2. Paper speed $100 \mathrm{~mm} / \mathrm{sec}$; time intervals in msec. In this and all subsequent figures: $A=$ atrial potentials in the His bundle electrogram; $H=H i s$ bundle potentials; $V=$ ventricular potentials; $S=$ stimulus artefacts.Top panel shows transient normalization of left bundle-branch block at a basic cycle length of 600 msec. Bottom panel shows permanent normalization at a cycle length of $700 \mathrm{msec}$. For details see text.

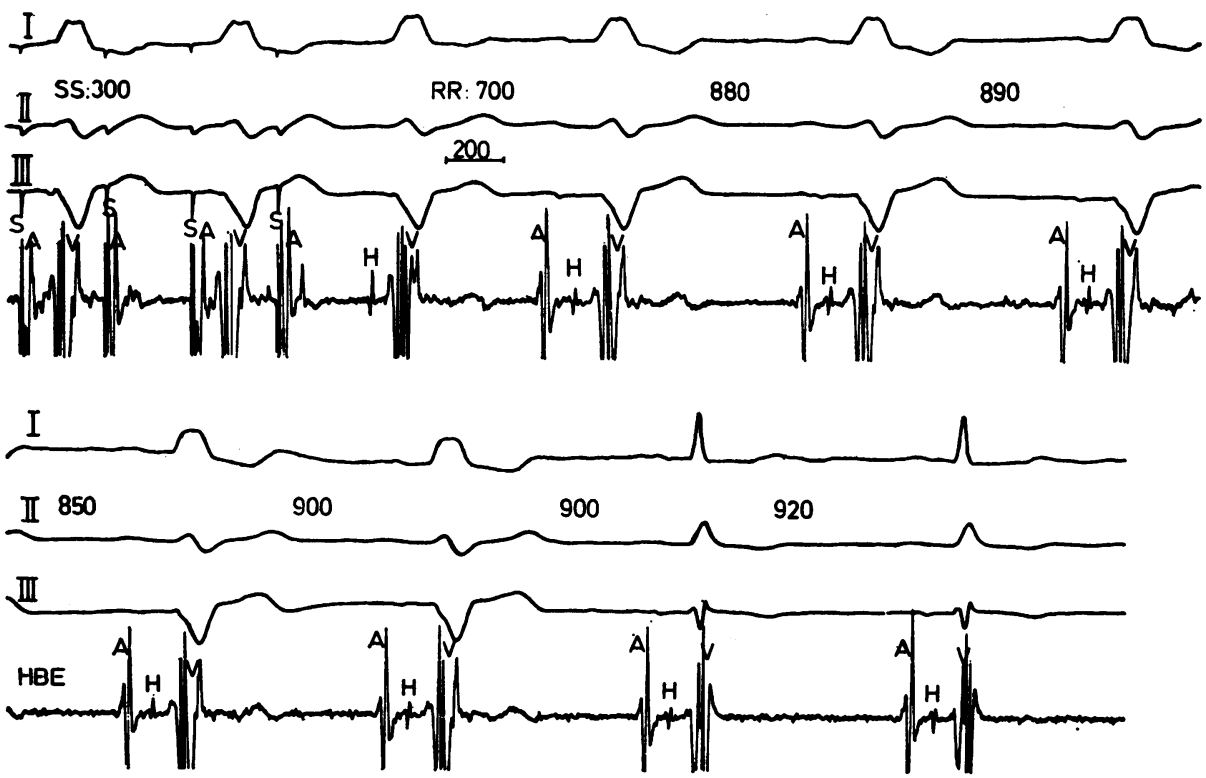

FIG. 3 Electrocardiogram (I,II,III) and His bundle recording (HBE) in a continuous recording (Case 4). After a period of rapid atrial stimulation (cycle length $=300 \mathrm{msec}$ ) left bundlebranch block persists at sinus rhythm. 
SS intervals were gradually prolonged, left bundle-branch block expectedly persisted at cycle lengths of 600 and $700 \mathrm{msec}$. Under these conditions, keeping the cycle length at 600 (Fig. 2, top panel) and $700 \mathrm{msec}$ (Fig. 2, bottom panel), respectively, a premature atrial depolarization is induced. The following 'post-extrasystolic' pause was long enough to ensure normal intraventricular conduction. While, at a cycle length of $600 \mathrm{msec}$, normalization is only transient, it persists at a cycle length of $700 \mathrm{msec}$; this, despite the longer 'postextrasystolic' interval of ventricular depolarizations occurring at atrial driving with a cycle length of $600 \mathrm{msec}$, where the premature atrial depolarization is blocked above the bundle of His.

\section{2) Postdrive depression of conductivity}

In Case 4 atrial stimulation with SS intervals of $300 \mathrm{msec}$ is carried out for 2 minutes (Fig. 3). At this cycle length RR intervals are only $600 \mathrm{msec}$ because of a $2: \mathrm{I}$ atrioventricular block above the His bundle. This is the critical ventricular cycle length at which left bundle-branch block appears. Therefore, all QRS complexes show left bundle-branch block configuration. After an abrupt termination of atrial stimulation, left bundle-branch block persists for the next five beats. However, the $R_{3} R_{4}$ interval has already reached the critical cycle length of $700 \mathrm{msec}$ where left bundle-branch block would usually disappear if the heart rate were slowly decreased.

\section{3) Frequency induced changes of refractory periods}

In the example of Fig. 4 refractory periods of the conducting system are determined using premature atrial depolarizations (Case 4). At sinus rhythm with a cycle length of $950 \mathrm{msec}$, the shortest possible $\mathrm{H}_{1} \mathrm{H}_{2}$ interval ( $\mathrm{FRP} \mathrm{P}_{\mathrm{AvN}}$ ) is $530 \mathrm{msec}$. At this $\mathrm{H}_{1} \mathrm{H}_{2}$ interval conduction in the left bundle-branch remains undisturbed (Fig. 4, top panel). At a basic cycle length of $660 \mathrm{msec}$ left bundle-branch block occurs when an $\mathrm{H}_{1} \mathrm{H}_{2}$ interval of $580 \mathrm{msec}$ is reached (Fig. 4, bottom panel). Full recovery time of the left bundle-branch $\left(F R T_{L B B}\right.$ ) is prolonged because of the shortening of basic cycle length. A more complete example of this phenomenon is seen in Fig. 5 (Case 2). At a cycle length of $700 \mathrm{msec}(86 / \mathrm{min})$ a premature atrial depolarization with a $S_{1} S_{2}$ interval of 420 msec leads to an $\mathrm{H}_{1} \mathrm{H}_{2}$ interval of $470 \mathrm{msec}$ with normal intraventricular conduction (Fig. 5a). Shortening the $S_{1} S_{2}$ interval to 410 msec results in a shortening of the $\mathrm{H}_{1} \mathrm{H}_{2}$ interval to $460 \mathrm{msec}$ and left bundle-branch block occurs
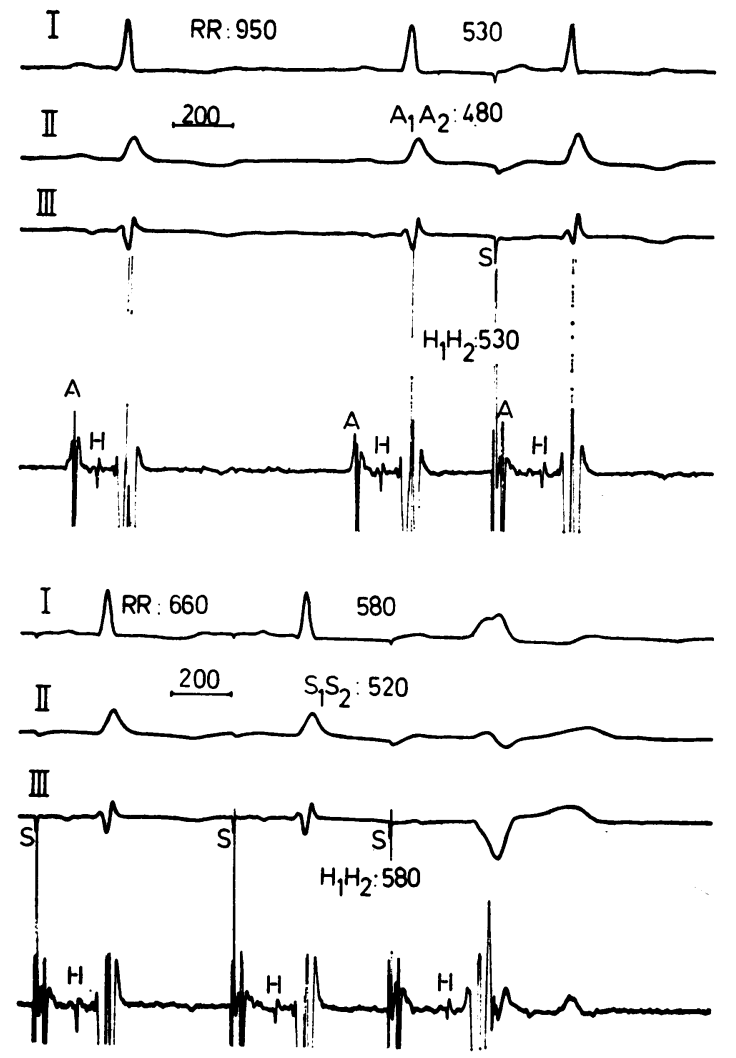

FIG. 4 Electrocardiogram (I, II, III) and His bundle electrogram of Case 4. Top panel shows that at sinus rhythm (cycle length $=950 \mathrm{msec}$ ) a premature atrial depolarization with a coupling interval of 480 msec $\left(A_{1} A_{2}\right)$ and an $H_{1} H_{2}$ interval of 530 msec is conducted without left bundle-branch block patterns Bottom panel: At a basic cycle length of $660 \mathrm{msec}$ a premature atrial depolarization with a coupling interval of $520 \mathrm{msec}$ and an $\mathrm{H}_{1} \mathrm{H}_{2}$ interval of 580 msec is conducted with left bundle-branch block pattern.

(Fig. 5b). This QRS configuration also exists at a $\mathrm{S}_{1} \mathrm{~S}_{2}$ interval of $360 \mathrm{msec}$ with an $\mathrm{H}_{1} \mathrm{H}_{2}$ interval of $450 \mathrm{msec}$ (Fig. 5c). No alterations in the $\mathrm{H}_{2} \mathrm{Q}_{2}$ intervals are observed. Further decrease of the $\mathrm{S}_{1} \mathrm{~S}_{2}$ intervals results in a pronounced nodal conduction delay with an $\mathrm{H}_{1} \mathrm{H}_{2}$ interval of $480 \mathrm{msec}$. At this interval the left bundle-branch is beyond its full recovery time $(470 \mathrm{msec})$ and intraventricular conduction is therefore normalized (Fig. 5d).

By shortening the basic cycle length to $600 \mathrm{msec}$ (roo/min), left bundle-branch block occurs at a longer $\mathrm{H}_{1} \mathrm{H}_{2}$ interval. In Fig. 5e a premature atrial depolarization with a $S_{1} S_{2}$ interval of $520 \mathrm{msec}$ 


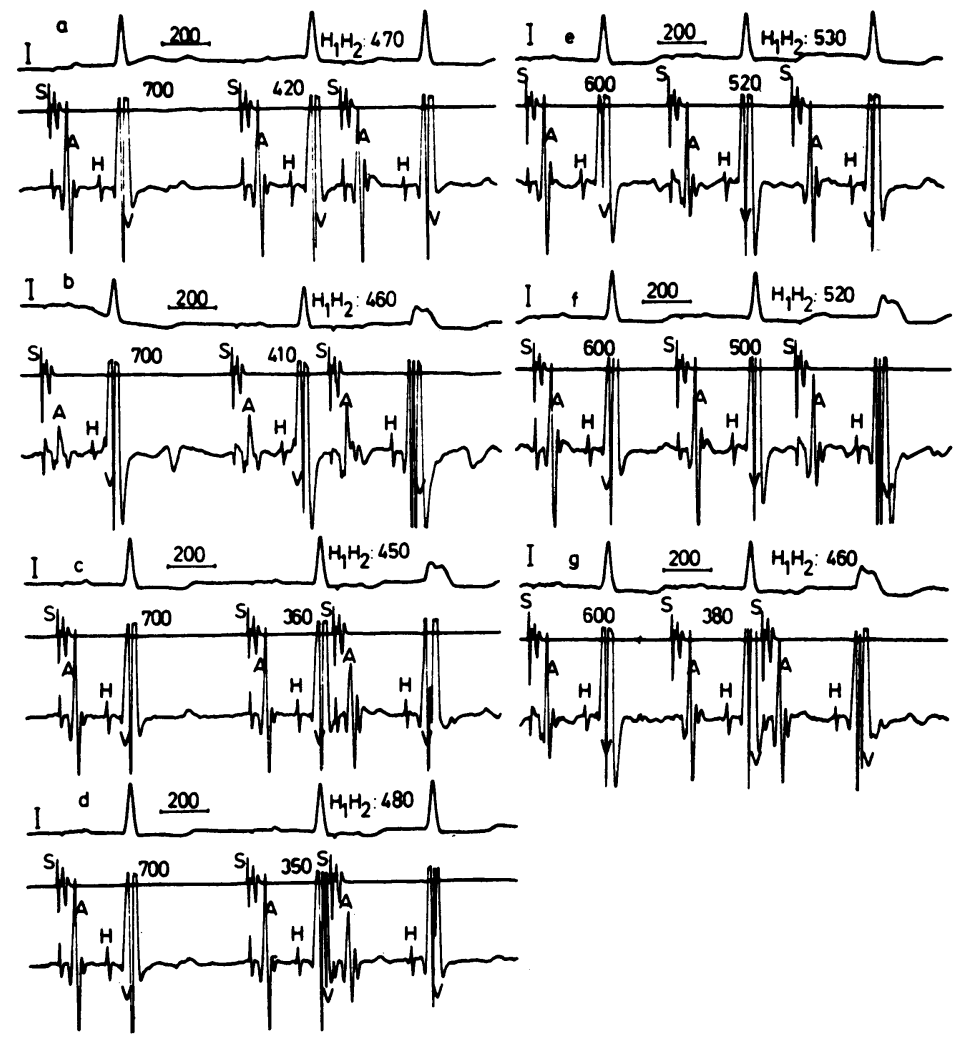

FIG. 5 (a-g) Electrocardiogram (I), atrial electrogram $(A E)$ and His bundle recording from Case 2. In a to d premature atrial depolarizations are introduced at progressively shorter coupling intervals during a basic driving cycle length of $700 \mathrm{msec}$. In e to $g$ premature atrial depolarizations with progressively shorter coupling intervals are introduced during a basic driving cycle length of $600 \mathrm{msec}$.

and an $\mathrm{H}_{1} \mathrm{H}_{2}$ interval of $530 \mathrm{msec}$ is conducted normally in the His-Purkinje system. Shortening the coupling interval to $500 \mathrm{msec}, \mathrm{H}_{1} \mathrm{H}_{2}(520 \mathrm{msec})$ reaches the full recovery time of the left bundlebranch, and left bundle-branch block occurs (Fig. 5f). Up to the shortest possible $S_{1} S_{2}$ interval at which atrioventricular nodal conduction is effective ( 380 $\mathrm{msec}$ ), all premature atrial depolarizations elicit a left bundle-branch block pattern (Fig. $5 \mathrm{~g}$ ).

Fig. 6 accounts for the relation between $S_{1} S_{2}$ intervals (abscissa) and $\mathrm{H}_{1} \mathrm{H}_{2}$ intervals (ordinate) in this case. At a basic cycle length of $700 \mathrm{msec}$ (heart rate: $86 / \mathrm{min}$ ) left bundle-branch block is present if $\mathrm{H}_{1} \mathrm{H}_{2}$ is below a critical value of $470 \mathrm{msec}$ (Fig. 6, left panel). If, at shorter $S_{1} S_{2}$ intervals, a nodal conduction delay leads to an $\mathrm{H}_{1} \mathrm{H}_{2}$ prolongation above $470 \mathrm{msec}$, conduction in the His-Purkinje system is normalized - 'gap I phenomenon' (Agha et al., 1973). At a basic cycle length of $600 \mathrm{msec}$ (heart rate: $100 / \mathrm{min}$ ) the critical $\mathrm{H}_{1} \mathrm{H}_{2}$ interval is prolonged to $530 \mathrm{msec}$ (Fig. 6, right panel). No gap phenomenon is elicited.

4) Unexpected improvement of conduction for premature atrial depolarizations

In Case 7, at a basic cycle length of $700 \mathrm{msec}$ $(86 / \mathrm{min})$, a premature atrial depolarization with an $S_{1} S_{2}$ interval of $600 \mathrm{msec}$ results in an incomplete left bundle-branch block (Fig. 7a). Decreasing the coupling interval, left bundle-branch block appears at an $\mathrm{H}_{1} \mathrm{H}_{2}$ interval of $580 \mathrm{msec}$ (Fig. 7b) and persists up to an $\mathrm{H}_{1} \mathrm{H}_{2}$ interval of $490 \mathrm{msec}$ (Fig. 7c). The $\mathrm{H}_{2} \mathrm{Q}_{2}$ interval remains unchanged. When this $\mathrm{H}_{1} \mathrm{H}_{2}$ interval further shortens, due to more prematurity of atrial depolorizations, intraventricular conduction unexpectedly returns to normal Fig. $7 \mathrm{~d}$ and e). Since the $\mathrm{H}_{2} \mathrm{Q}_{2}$ interval remains unchanged, normalization due to gap II can be 

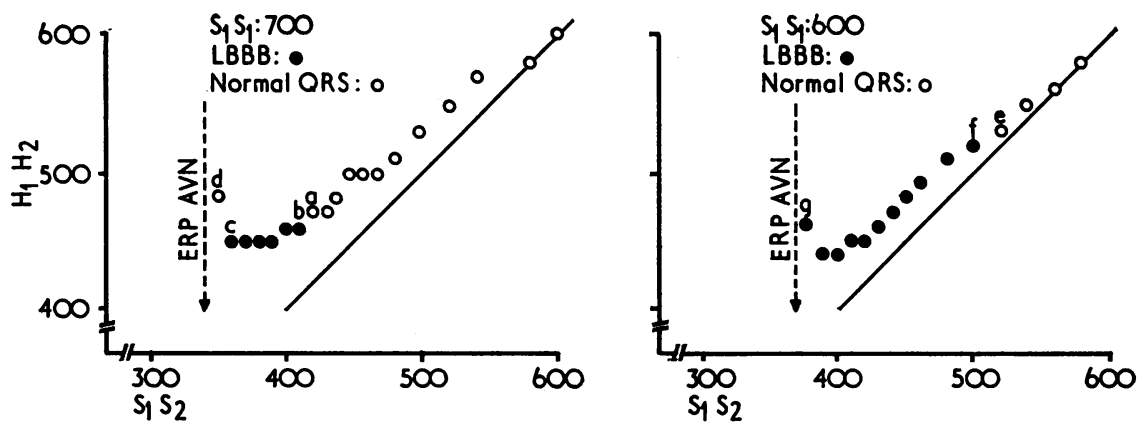

FIG. 6 Graph shows the relation between atrial depolarizations $\left(A_{1} A_{2}=S_{1} S_{2}\right.$ intervals on abscissa) and His bundle depolarizations $\left(\mathrm{H}_{1} \mathrm{H}_{2}\right.$ intervals on ordinate) for premature atrial depolarizations in Case 2 at a basic cycle length of $700 \mathrm{msec}$ (left panel) and at a basic cycle length of $600 \mathrm{msec}$ (right panel).

ruled out, and the normalization is most likely explained by a gap III phenomenon, i.e. supernormal phase of conduction (Agha. et al., 1973). At a coupling interval of $300 \mathrm{msec}, \mathrm{H}_{1} \mathrm{H}_{2}$ is augmented to $490 \mathrm{msec}$ because of nodal conduction delay (Fig. 7f). Consequently left bundle-branch block appears again (gap I phenomenon). The graph (Fig. 8) demonstrates the dependence of $\mathrm{H}_{1} \mathrm{H}_{2}$ intervals (identical to $R_{1} R_{2}$ intervals) on the coupling intervals of premature atrial depolarizations in this case.

\section{5) Paradoxical improvement of conduction at increased heart rates}

Unexpected improvement of conduction in the left bundle-branch was observed by gradually increasing driving frequency. In Case 7 (Fig. 9) incomplete left bundle-branch block occurs at a basic cycle length of $600 \mathrm{msec}$ (Fig. 9b) which progresses to complete left bundle-branch block at a cycle length of $500 \mathrm{msec}$. With unchanged $\mathrm{HQ}$ intervals of $50 \mathrm{msec}$, this configuration exists at cycle lengths of $500 \mathrm{msec}$ (Fig. 9c) and $400 \mathrm{msec}$,
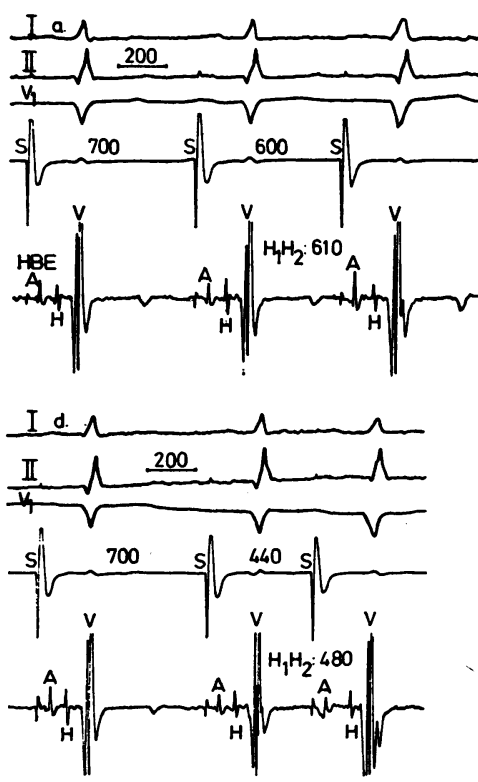
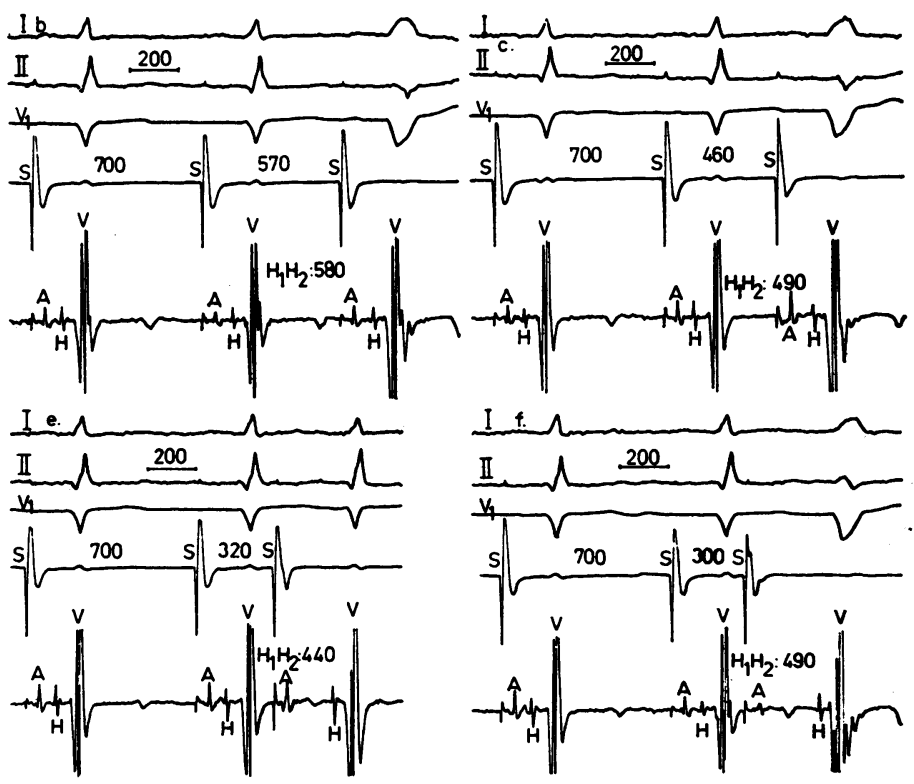

FIG. 7 Electrocardiogram (I, II, VI), atrial electrogram, and His bundle recording (HBE) of Case 7. Panel a to $f:$ premature atrial depolarizations are introduced at progressively shorter coupling intervals during a basic driving cycle of $700 \mathrm{msec}$. 


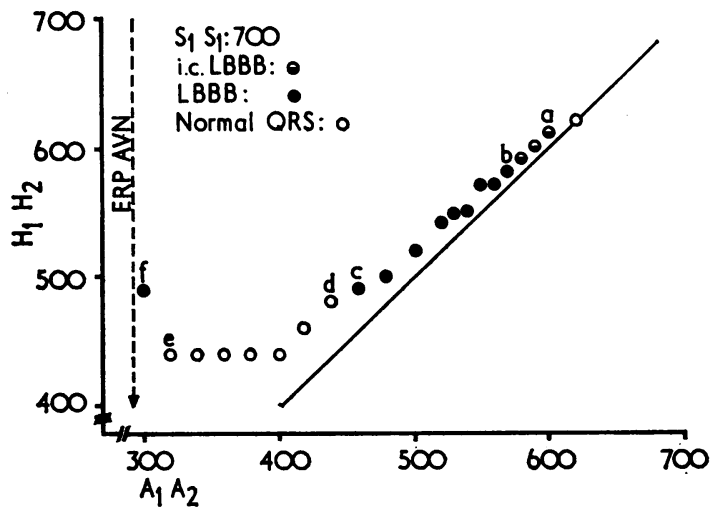

FIG. 8 Graph showing the relation between the coupling intervals of premature atrial depolarizations $\left(A_{1} A_{2}\right.$ intervals) and the $H_{1} H_{2}$ intervals in Case 7 (same patient as in Fig. 7). Half-filled circle (i.c. $L B B B)=$ incomplete left bundle-branch block. Filled circle $(L B B B)=$ complete left bundle-branch block configuration of the induced beat. Open circle $=$ normal configuration of $Q R S$.

respectively. In a range between 420 and $490 \mathrm{msec}$ (I43 to $125 / \mathrm{min}$ ), alternating normalization of QRS is found. This range is demonstrated in Fig. 9d and e. At a SS interval of $420 \mathrm{msec}$, alternating normalization of QRS occurs (Fig. 9d) and then disappears at an SS interval of $490 \mathrm{msec}$ (Fig. 9e). An identical critical range was found regardless of whether it was reached by increasing or decreasing heart rate.

The findings of all patients studied are summarized in Tables I and 2. Intracardiac registration showed unimpaired conduction at sinus rhythm. Under pacing there was a characteristic SS interval at which left bundle-branch block reproducibly appeared if the heart rate was gradually increased. Decreasing the heart rate, left bundle-branch block persisted to an SS interval which was always 80 to $170 \mathrm{msec}$ longer than that found when the heart rate was increased. Using a different approach (outlined under $I \mathrm{~b}$ ), the findings suggest an interdependence between the critical SS intervals and the time in which these intervals were reached. After a driving period of two minutes (ventricular rate 100 to $170 / \mathrm{min}$ ), left bundle-branch block persisted in all cases at cycle lengths beyond the critical range (zone of 'linking') previously established. Full recovery time of the left bundle-branch did not shorten in 6 patients when heart rate was accelerated (Table 2). In 4 patients, an increase was found if basic heart rate was within the zone of 'linking'.
Measurements of refractory periods at different heart rates were not carried out in Case 3 because of technical reasons.

In 3 patients (Cases, 3, 5, and 6) gap III phenomena were observed, and in 2 patients (Cases 3 and 6) a paradoxical improvement of conduction in the left bundle-branch appeared at a higher driving rate.

\section{Discussion}

The phenomenon of 'linking' or 'overlapping' has been reported by several authors (Rosenbaum et al., 197I ; Fisch, Zipes, and McHenry, 1973). Rosenbaum et al. (1973) for instance, observed that, 'the critical rate phase III block will be higher when the rate increases and lower when it decreases'. One acceptable explanation offered by these investigators is that persistence of block at a decreasing heart rate is due to concealed retrograde penetration via the intact His-Purkinje system and the myocardium. In this way, depolarization in the zone of block may be delayed and recovery time altered accordingly. This interpretation, however, does not explain the findings in at least 2 of our patients (Cases 2 and 7, Fig. 2). Though intermittent normalization after an accordingly long postdrive pause was present, left bundle-branch block occurred again in the critical frequency range. During this intermittent normalization the zone of block was anterogradely depolarized without delay, so that concealed retrograde penetration can be excluded.

Inhibiting automaticity by rapid stimulation is a well-known phenomenon ( $\mathrm{Lu}$, Lange, and Brooks, 1965) and is clinically apparent in the postdrive slowing of sinus rate - 'overdrive suppression'. Observations from our own laboratory have shown that after rapid stimulation conduction in accessory pathways remains impaired at frequencies where conduction over this path was normally stable (Neuss, Nowak, and Schlepper, 1973). Similar findings regarding the left bundle-branch block could be ascertained in all patients in the study. After abrupt termination of atrial stimulation (ventricular rate I00 to $170 / \mathrm{min}$ ), left bundle-branch block persisted at sinus rhythm for variable periods. These findings are indicative of frequency-induced changes of conductivity in the left bundle-branch. If one assumes that there are characteristic conduction properties for a given frequency, the steady state of these properties is reached with delay when heart rate is changed. Linking as well as postdrive depression can be explained in this fashion.

If, starting from a frequency with normal conduction, heart rate is gradually increased, conduction properties adjust to the adequate heart rate with 

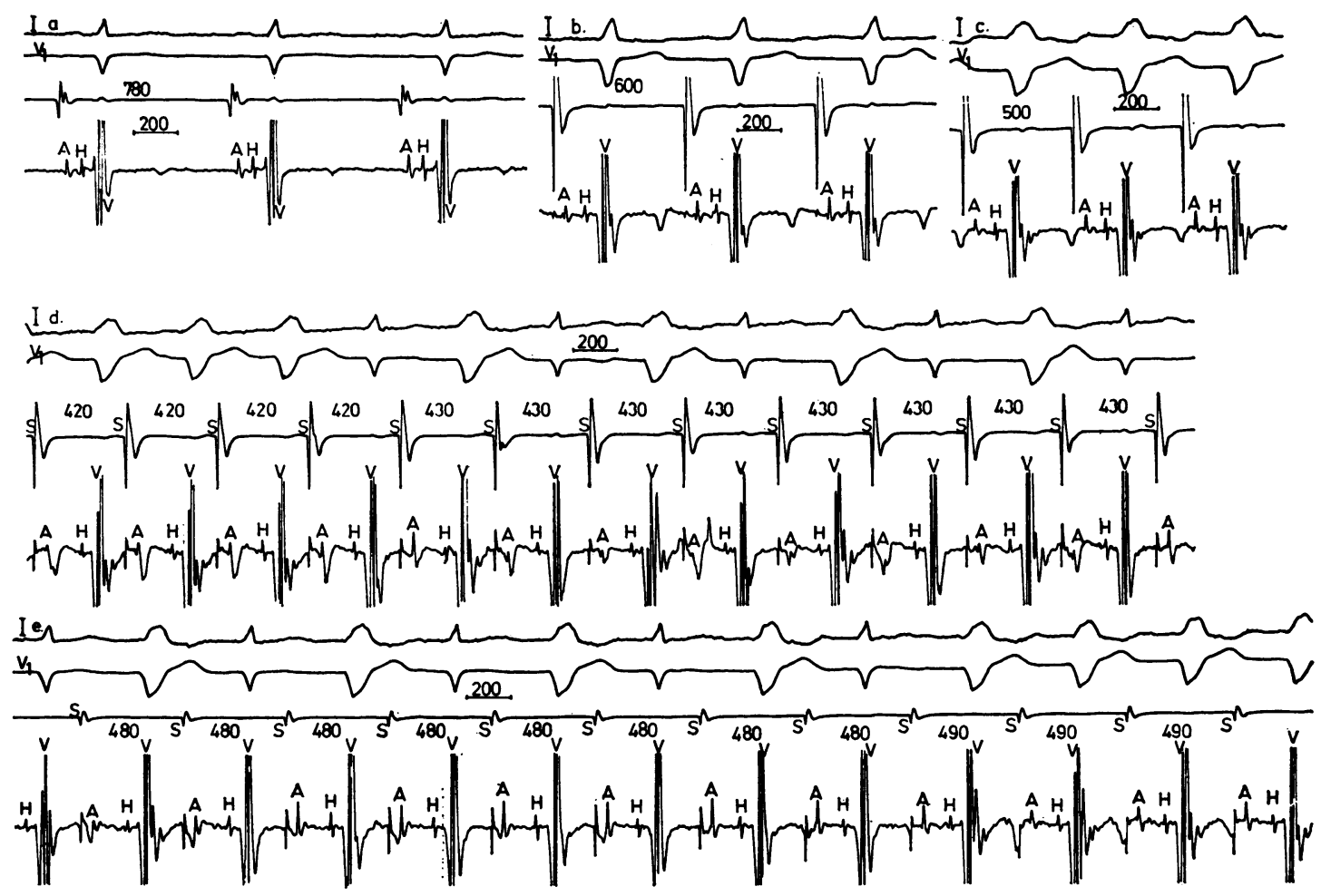

FIG. 9 Electrocardiogram $(I, V I)$, atrial electrogram, and His bundle recording in Case 7. a) normal conduction in the left bundle-branch at sinus rhythm. b) incomplete left bundle-branch block at a cycle length of 600 msec. c) complete left bundle-branch block at a cycle length of 500 msec. d) and e) alternating normalization of $Q R S$ is found in the range between the cycle lengths of 420 and 480 msec.

delay, and left bundle-branch block appears at a characteristic heart rate. If, on the other hand, heart rate is gradually decreased starting at a frequency for which block has been confirmed, normalization will occur at a lower heart rate owing to the slow levelling of time-dependent conduction properties. These findings suggest that linking might be abolished or the critical frequency range could become very narrow if alterations in heart rate occur slowly enough. Retardation in the occurrence of left bundle-branch block at abrupt frequency increases or the lag in normalization of QRS after abrupt slowing can be explained by the same mechanism.

Rate-dependent left bundle-branch block is said to be due to an increased recovery time of the involved branch. In their cases, Rosenbaum et al. (1973) explain these changes in recovery time by an augmented repolarization period which is caused by a prolongation of phase 3 - or perhaps phase $2-$ of the action potentials within the area of block.
Accordingly their term 'phase 3 block' was coined. Full recovery time of the left bundle-branch was clearly prolonged at slow heart rates in 3 of our patients (Cases 3, 5, and 7), while in Cases $I$ and 2 they were within normal range (Wit et al., 1970; Schuilenburg and Durrer, 1973). During acceleration of heart rate the expected shortening of the full recovery time (Moe and Mendez, I97I) failed to appear in 6 patients. If full recovery time was determined at a basic heart rate within the linking zone, then a prolongation was observed in 4 patients (Cases $1,2,4$, and 6). Normally the duration of action potential in the His-Purkinje systemis shortened with increasing heart rate (Hoffman and Cranefield, 1960). This observation therefore allows the interpretation that in frequency-dependent left bundle-branch block an anticipated shortening of action potential duration in the zone of block either does not occur or the duration of action potential becomes prolonged. Animal experiments supporting 
TABLE I Summarized values

\begin{tabular}{|c|c|c|c|c|c|c|c|}
\hline \multirow{4}{*}{$\begin{array}{l}\text { Case } \\
\text { No. } \\
\mathbf{I} \\
2\end{array}$} & \multirow{2}{*}{\multicolumn{2}{|c|}{$\begin{array}{l}\text { Age } \\
(y r), \text { sex }\end{array}$}} & \multirow{4}{*}{$\begin{array}{l}\text { Diagnosis } \\
\begin{array}{l}\text { Myocarditis } \\
\text { Coronary heart } \\
\text { disease }\end{array}\end{array}$} & \multirow{2}{*}{\multicolumn{2}{|c|}{$\begin{array}{l}\text { Range of linking } \\
(R R \text { in msec) } \\
a^{\star} \quad b^{\star}\end{array}$}} & \multicolumn{2}{|c|}{ Postdrive depression of conductivity } \\
\hline & & & & & & \multirow{2}{*}{$\begin{array}{l}\text { Stimulated rate } \\
\mathrm{I67} / \mathrm{min}\end{array}$} & \multirow{2}{*}{$\begin{array}{l}\text { Longest } R R \text { interval with left } \\
\text { bundle-branch block in } \\
\text { postoperative period }\end{array}$} \\
\hline & 39 & $\mathbf{M}$ & & 480 & 550 & & \\
\hline & 67 & F & & 550 & 710 & I $50 / \mathrm{min}$ & $830 \mathrm{msec}$ \\
\hline $\begin{array}{l}3 \\
4\end{array}$ & & $\begin{array}{l}F \\
F\end{array}$ & $\begin{array}{l}\text { Myocarditis } \\
\text { Coronary heart }\end{array}$ & 700 & 820 & $120 / \mathrm{min}$ & $900 \mathrm{msec}$ \\
\hline & & & disease & 540 & 700 & $100 / \mathrm{min}$ & $900 \mathrm{msec}$ \\
\hline 5 & & F & $\begin{array}{l}\text { Coronary heart } \\
\text { disease }\end{array}$ & 670 & 840 & $150 / \mathrm{min}$ & $980 \mathrm{msec}$ \\
\hline 6 & 63 & $\mathbf{M}$ & $\begin{array}{l}\text { Coronary heart } \\
\text { disease }\end{array}$ & 620 & 740 & $150 / \mathrm{min}$ & $880 \mathrm{msec}$ \\
\hline 7 & 47 & $\mathbf{F}$ & Myocarditis & 570 & 670 & $150 / \mathrm{min}$ & $820 \mathrm{msec}$ \\
\hline
\end{tabular}

$\star_{a}=S S$ at which left bundle-branch block appears; $\star_{b}=S S$ at which left bundle-branch block disappears.

TABLE 2 Summarized values (msec) of all patients in study

\begin{tabular}{|c|c|c|c|c|c|}
\hline $\begin{array}{l}\text { Case } \\
\text { No. }\end{array}$ & $\begin{array}{l}\text { Basic } \\
\text { cycle } \\
\text { length } \\
S_{1} S_{1}\end{array}$ & $\begin{array}{l}\text { Functional refractory } \\
\text { period of } A V \text { node } \\
H_{1} H_{2}\end{array}$ & $\begin{array}{l}\text { Effective refractory } \\
\text { period of } A V \text { node } \\
A_{1} A_{2}\end{array}$ & $\begin{array}{l}\text { Full recovery time of } \\
\text { left bundle-branch } \\
\mathrm{H}_{1} \mathrm{H}_{2}\end{array}$ & $\begin{array}{l}\text { Supranormal phase of } \\
\text { conduction in left } \\
\text { bundle-branch } \\
\mathrm{H}_{1} \mathrm{H}_{2}\end{array}$ \\
\hline \multirow[t]{3}{*}{$\mathbf{I}$} & 700 & 410 & $270^{\star}$ & 420 & - \\
\hline & 600 & 410 & 330 & 420 & - \\
\hline & 500 & 400 & 320 & 440 & - \\
\hline \multirow[t]{4}{*}{2} & 1100 & 440 & $270^{\star}$ & 470 & - \\
\hline & 800 & 450 & 340 & 460 & - \\
\hline & 700 & 450 & 360 & 460 & - \\
\hline & 600 & 440 & 370 & 520 & - \\
\hline 3 & 950 & 490 & $320 *$ & 680 & $600-570$ \\
\hline 4 & $\begin{array}{l}950 \\
660\end{array}$ & $\begin{array}{l}530 \\
530\end{array}$ & $\begin{array}{l}390 \\
420\end{array}$ & $\begin{array}{r}<530 \\
580\end{array}$ & 二 \\
\hline \multirow[t]{2}{*}{5} & 900 & 460 & 320 & 650 & - \\
\hline & 800 & 440 & 350 & 650 & - \\
\hline \multirow[t]{2}{*}{6} & 900 & 430 & $270^{\star}$ & 560 & $450-430$ \\
\hline & 700 & 440 & 340 & 600 & - \\
\hline \multirow[t]{3}{*}{7} & 900 & 440 & $270^{\star}$ & 600 & $460-440$ \\
\hline & 800 & 430 & $270^{\star}$ & 610 & $480-430$ \\
\hline & 700 & 440 & 290 & 610 & $480-440$ \\
\hline
\end{tabular}

$\star$ Effective refractory period of atrioventricular conduction given as effective refractory period of atria; $-=\mathrm{Did}$ not occur. For abbreviations and details see text.

this possibility do not exist. The assumption of Rosenbaum et al. (1973) that an action potential in injured tissue could last up to $r \cdot 8 \mathrm{sec}$ is, at best, hypothetical, and experimental proof is lacking. In explaining our findings it must be pointed out that full recovery time is not dependent on phase 3 of the action potential alone. The full recovery time is defined by the shortest possible coupling interval of premature depolarizations conducted without delay. This is possible only if upstroke velocity of the action potential is not significantly diminished. Since upstroke velocity of the action potential depends on membrane potential (Weidmann, 1955), it seems safe to assume that blockage in frequencydependent left bundle-branch block is caused by a low membrane potential. In phase 3 block it might be due to incomplete repolarization, and in phase 4 block to spontaneous diastolic repolarization. This explanation, however, cannot be applied to all of our observations. 
From studies of the effects of certain antiarrhythmic agents we can deduce the following.

I) That upstroke velocity of the action potential of induced premature depolarizations may be conspicuously reduced, even after repolarization has been completed and a normal membrane potential is restored (Szekeres and VaughanWilliams, 1962).

2) These antiarrhythmic drugs, furthermore, may lead to a reduction of upstroke velocity during acceleration of heart rate (Tritthart, Fleckenstein, and Fleckenstein, 1972).

3) The characteristic $d V / d t$ max for a certain heart rate is reached with lag when driving rate is changed (Heistracher, 197I). These kinds of antiarrhythmic drugs (h-type) are thought to retard the regeneration of the sodium carrier (Antoni, 1972). At each heart rate there is a characteristic steady state between activation and regeneration of sodium carriers, whose availability determines the rapid sodium influx and thus limits $\mathrm{dV} / \mathrm{dt} \max$ (Heistracher, 197I).

Assuming that in frequency-dependent left bundlebranch block the regeneration of the sodium carrier in a defined area of the left bundle-branch is retarded, occurrence of block could be expected at a critical heart rate. The phenomenon of linking and postdrive depression of conductivity can also be explained by this theory. In addition, the change in heart rate and the concomitant lag of the characteristically steady state between regeneration and activation of the sodium carrier would explain our observations. In accelerating heart rate the dissociation between duration of the action potential and restitution of $d V / d t$ max may become more pronounced. Thus, in spite of the expected shortening of the action potential in the zone of block, there is a prolongation of full recovery time.

Another mechanism might be involved. If, in a focal lesion of a bundle-branch, the intact proximal and distal parts are connected by small strands of Purkinje fibres, there can be an impedance mismatch. This means, that under certain conditions determined by the geometry of the lesion, i.e. the insertion of the few strands of fibres into the intact cable, small changes of the input (dV/dt max and amplitude of action potential) determine the success or failure of propagation. It should be assumed that the input current, provided by a small number of cells, is drained off by low resistance communications between cells at the junction, leaving the remaining current possibly insufficient to bring a larger cell population to threshold. This mechanism might play a role in impulse propagation in the WPW syndrome (Fuente, Sasyniuk, and Moe,
197I) and at Purkinje fibre muscle junctions (Mendez et al., 1969). Even slight alterations of functional properties of Purkinje fibres might produce the observed phenomena if the margin of safety for propagation is low because of impedance mismatch.

It is unlikely that the gap III phenomena observed in 3 patients in the group under study was accidental and the following interpretation is offered. Block is caused by a circumscribed lesion in the left bundle-branch. Input current is critically diminished at higher driving rates and for premature atrial depolarizations. Whether there is further conduction beyond this area depends on the quality of the arriving action potential and on the membrane potential and threshold potential at the junction. The protodiastolic decrease of excitation threshold, which according to Brooks et al. (1955) is 5 to 15 per cent in $\mathrm{mA}$, allows the propagation of an action potential with diminished amplitude and upstroke velocity (conduction due to supernormal phase of excitability).

Since in two of these patients paradoxical improvement of conduction was observed at higher driving rates, this too may be related to the same mechanism. At a frequency of $100 / \mathrm{min}$ (Fig. IOa) upstroke velocity of the action potential in the zone of block ( $b$ in the ladder diagram) is critically diminished (indicated by the broken lines). Distal to this area ( $\mathrm{d}$ in the ladder diagram), conduction is blocked because of subthreshold excitation. These distal parts of the left bundle-branch are therefore retrogradely depolarized; repolarization, therefore, is delayed. In the schematic drawing of Fig. Ioa and $b$, the refractory period of this zone is symbolized by horizontal bars. After this period there is a phase of supernormal excitability (tessellated area). If heart rate is accelerated, sub-threshold excitation may reach the distal zone in this phase of supernormal excitability and reinstitution of normal conduction will result with normalized QRS complexes (Fig. Iob). Because of the ensuing anterograde spread of excitation in the distal part of the left bundle-branch, the concomitant course of repolarization is altered. Therefore, the following excitation meets unfavourable conditions of conductivity and may be blocked. In this instance the delayed retrograde penetration in the distal parts of the left bundle-branch causes lag of repolarization. Again the following excitation wave arrives in the supernormal phase of excitability. A shift in the sequence of depolarization, and therefore repolarization, takes place, and may be the reason for the alternate normalization of QRS.

An alternative explanation may be offered assuming different degrees of blockages within the left 
A

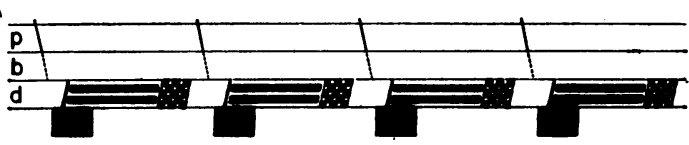

B
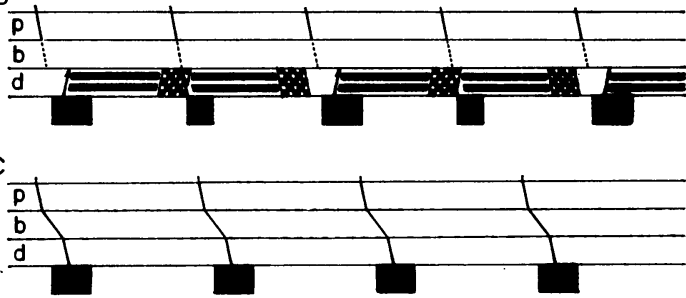

D

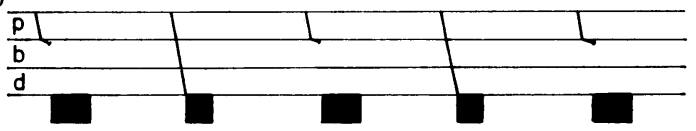

FIG. Io Schematic presentation of the mode of conduction in Case 7 (see Fig. 9). In the ladder diagram only the conduction sequence in the left bundle-branch is shown. $p=z$ zone proximal to the area of block; $b=$ zone of block; $d=$ area distal to the zone of block. For details see text.

bundle-branch. At a relatively low heart rate there may be conduction delay in the zone of block (Fig. IOc). This rate-dependent conduction delay in the bundle-branch will result in incomplete left bundlebranch block pattern, while at a slightly higher rate, complete left bundle-branch block pattern might occur. This is in accordance with the observation in Case 7 (Fig. 9b and c). At a higher heart rate 2: I block in the left bundle-branch would be established accordingly. Under these conditions alternate normalization of QRS will result (Fig. Iod).

The interpretations of our findings are, in part, speculative. More detailed studies are needed to ascertain whether frequency-dependent blockage in the His-Purkinje system may be caused by a disturbance between activation and regeneration of $\mathrm{Na}{ }^{+}$carrier.

\section{References}

Agha, A. S., Castellanos, A., Wells, D., Ross, M. D., Befeler, B., and Myerburg, R. J. (I973). Type I, type II and type III gaps in bundle-branch conduction. Circulation, 47, 325.

Antoni, H. (1972). Über den elektrophysiologischen Mechanismus der Refraktärperiode des Myokards und ihre Beeinflussung durch Antiarrhythmika. In Die therapeutische Anwendung beta-sympatholytischer Stoffe, p. I91. Ed. by H. J. Dengler. Schattauer-Verlag, Stuttgart.

Bauer, G. E. (1964). Bundle-branch block under voluntary control. British Heart fournal, 26, 167.

Brooks, C. McC., Hoffmann, B. F., Suckling, E. E., and
Orias, O. (1955). Excitability of the Heart. Grune \& Stratton, New York.

Comeau, W. J., Hamilton, J. G. M., and White, P. D. (1938). Paroxysmal bundle-branch block associated with heart disease. American Heart fournal, 15, 276.

Fisch, C., Zipes, D. P., and McHenry, P. L. (1973). Rate dependent aberrancy. Circulation, 48, 7 I4.

Fuente, D., Sasyniuk, B., and Moe, G. K. (197I). Conduction through a narrow isthmus in isolated canine atrial tissue. Circulation, 44, 803.

Heistracher, P. (1971). Mechanism of action of antifibrillatory drugs. Naunyn-Schmiedeberg's Archiv für experimentelle Pathologie und Pharmakologie, 269, 199.

Hoffman, B. F., and Cranefield, P. F. (1960). Electrophysiology of the Heart. McGraw-Hill, New York.

Lewis, T. (1913). Certain physical signs of myocardial involvement. British Medical fournal, r, 484.

Lu, H. H., Lange, G., and Brooks C. McC. (1965). Factors controlling pacemaker action in cells of the sinoatrial node. Circulation Research, 17, 460.

Mendez, C., Mueller, W. J., Merideth, J., and Moe, G. K. (1969). Interaction of transmembrane potentials in canine Purkinje fibers and at Purkinje fiber-muscle junctions. Circulation Research, 24, 36r.

Moe, G. K., and Mendez, C. (1971). Functional block in the intraventricular conduction system. Circulation, 43, 949.

Neuss, H., Nowak, F., and Schlepper, M. (1973). Changes of conduction properties of anomalous pathways in cases with W.P.W.-syndrome. Zeitsechrift für Kardiologie, 62, 489.

Rosenbaum, M. B., Elizari, M. V., Lazzari, J. O., Halpern, M. S., and Nau, G. J. (1971). Bilateral bundle branch block: its recognition and significance. In Cardiovascular Clinics. Vol. 2, p. 152. Ed. by A. N. Brest. F. A. Davis, Philadelphia.

Rosenbaum, M. B., Elizari, M. V., Lazzari, J. O., Halpern, M. S., Nau, G. J., and Levi, R. J. (r973). The mechanism of intermittent bundle branch block: relationship to prolonged recovery, hypopolarization and spontaneous diastolic depolarization. Chest, $63,666$.

Scherlag, B. J., Lau, S. H., Helfant, R. H., Berkowitz, W. D., Stein, E., and Damato, A. N. (1969). Catheter technique for recording His bundle activity in man. Circulation, 39, I3.

Schuilenberg, R. M., and Durrer, D. (1973). Rate-dependency of functional block in the human His bundle and bundle branch-Purkinje system. Circulation, 48, 526.

Szekeres, L., and Vaughan-Williams, E. M. (1962). Antifibrillatory action. Fournal of Physiology, 160, 470.

Tritthart, H., Fleckenstein, B., and Fleckenstein, A., Jr. (197I). Some fundamental actions of antiarrhythmic drugs on the excitability and the contractility of single myocardial fibers. Naunyn-Schmiedeberg's Archiv für experimentelle Pathologie und Pharmakologie, 269, 212.

Vesell, H. (I94I). Critical rates in ventricular conduction. Unstable bundle branch block. American fournal of the Medical Sciences, 202, 198.

Weidmann, S. (1955). The effect of the cardiac membrane potential on the rapid availability of the sodium-carrying system. Fournal of Physiology, 127, 213.

Wit, A. L., Weiss, M. B., Berkowitz, W. D., Rosen, K. M., Steiner, C., and Damato, A. N. (1970). Patterns of atrioventricular conduction in the human heart. Circulation Research, 27, 345.

Requests for reprints to Dr. M. Schlepper, KerckhoffKlinik, Benekestr. 6-8, 635 Bad Nauheim, West Germany. 